\title{
A coagulation-flocculation process combined with continuous adsorption using eggshell waste materials for phenols and PAHs removal from landfill leachate
}

\author{
Jaradat A. $\mathbf{Q}^{1^{\dagger}}$, Shtayat A. R. ${ }^{2}$, Sana'a Odat ${ }^{3}$ \\ ${ }^{1}$ Department of Civil Engineering, Yarmouk University, Irbid, Jordan \\ ${ }^{2}$ Attarat Power Company, Amman, Jordan \\ ${ }^{3}$ Department of Earth\& Environmental Sciences, Yarmouk University, Irbid, Jordan
}

\begin{abstract}
A sequential treatment consisting of coagulation/flocculation followed by transport column experiment was adopted and used in this work for the treatment of landfill leachate containing phenols and polycyclic aromatic hydrocarbons (PAHs). Coagulation experiment was performed in a standard jar test apparatus using alum as coagulant material. In column experiments, natural eggshell material was used as filter media after calcinations at $750^{\circ} \mathrm{C}$ either separately or combined with granular activated carbon (GAC). Alum addition at a predetermined optimum dose (3.5 g/L) caused a reduction in total suspended solids (TSS), chemical oxygen demand (COD), total phenols, and total (PAHs) by $82 \%, 32 \%, 24 \%$, and $34 \%$ respectively. Specific PAHs analysis revealed higher binding affinity of more hydrophobic PAHs toward particles with 50\% reduction than those of less hydrophobic PAHs with only $6 \%$ reduction. The results obtained from the transport column experiments indicate that calcined eggshell (ESC) particularly when applied as a mixture with GAC can be used as promising adsorbent for both phenols and PAHs. 95\% of phenols and PAHs were removed during the first 1,500 pore volumes (PV) of column operation while $>80 \%$ were obtained at the end of the experiment $(3,500 \mathrm{PV})$.
\end{abstract}

Keywords: Coagulation, Eggshell, Landfill Leachate, PAHs, Phenols, Removal Efficiency

\section{Introduction}

Landfilling remains an integral part of solid waste management practices particularly in developing countries despite the intensive efforts directed toward solid waste recovery options. Improper Landfilling activities have been found as one of the serious threats to the environment. When waste is placed in landfills, series of complex physicochemical and biological processes take place leading to the production of both liquid and gaseous emissions. As water percolate through the solid waste matrix, leachate containing organic and inorganic components is produced and accumulate at the bottom of the landfill site and may percolate through the soil in case of improper lining resulting in soil and GW contamination [1]. The leachate is characterized by a very complex composition and high concentrations of chemical oxygen demand (COD), adsorbable organic halides (AOX), polycyclic aromatic hydrocarbons (PAHs), phenols and reduced nitrogen [2].

This is an Open Access article distributed under the terms of the Creative Commons Attribution Non-Commercial License (http://creativecommons.org/licenses/by-nc/3.0/) which permits unrestricted non-commercial use, distribution, and reproduction in any medium, provided the original work is properly cited.

Copyright (C) 2022 Korean Society of Environmental Engineers
The recognition of landfill leachate impact on the environment has forced authorities to fix and strengthen requirements for pollution control. Several studies have been carried out to address a reasonable treatment of landfill leachate by using various approaches. Biological treatment processes for leachate containing high concentrations of BOD have been widely studied and adopted under aerobic and anaerobic conditions [3]. Generally, biological treatment of landfill leachate has proven to be very efficient in removing contaminants at the early stages when the $\mathrm{BOD}_{5} / \mathrm{COD}$ ratio of the leachate is high. This ratio, however, decreases with the age of the landfill and later the process becomes less effective. This may be due to the presence of toxic substances, which may inhibit microbial activities [4]. Hence additional physicochemical treatment is normally necessary to decrease the concentration of contaminants prior to biological treatment [5].

Several physicochemical processes such as oxidation, sedimentation, coagulation and flocculation, ion exchange, membrane

Received March 11, 2021 Accepted May 01, 2021

${ }^{\dagger}$ Corresponding author

E-mail: ayman.j@yu.edu.jo

Tel: +962797387350 Fax: +96227211192

ORCID: 0000-0002-6514-5214 
filtration, chemical precipitation, reverse osmosis, air stripping, and adsorption have been used effectively for landfill leachate treatment of specific pollutants or as a pre-treatment or last purification step [2-8] While these technologies require high cost, implementing an efficient, cost effective, and environmentally acceptable method for leachate treatment is of great value. Recently, various low-cost adsorbents derived from agricultural waste, industrial by-products or natural materials, have been intensively investigated. Some of these materials include bottom ash [9], palm ash [10], zeolite [11], marine sand and saw dust [12, 13], limestone and activated carbon [14], Walnut shells [15], and diatomaceous earth materials [16].

The use of waste materials as low-cost adsorbents is attractive due to their contribution in the reduction of costs for waste disposal and environmental protection. Over the last two decades natural eggshell waste materials (ES) have been used widely as adsorbents for the removal of variety of organic and inorganic contaminants from wastewater streams. Worldwide consumption of hen eggs is quite high, which results into availability of large amount of discarded egg shell wastes. The eggshells are characterized by a porous, fibril structure and high surface area with special functional groups such as hydroxyl (-OH), thiol (-SH), Carboxyl (-COOH), and amino (-NH2) suggesting its good adsorption properties [17, 18]. Each ES has been estimated to contain between 7,000 to 17,000 pores [17]. Furthermore, it has been reported that thermal treatment of eggshell at temperature $>700^{\circ} \mathrm{C}$ increases its adsorptive capacity by increasing the surface area. Tsai et al. [19] reported an increase in the surface area of the eggshells from 1.05 to $1.85 \mathrm{~m}^{2} / \mathrm{g}$ and an increase in the particle porosity from 0.018 to $0.051 \mathrm{~g} / \mathrm{cm}$ after calcinations at $1,000^{\circ} \mathrm{C}$. Thus, eggshells are a potential world-wide available by-product and environmentally reasonable adsorbent.

A review of the literature reveals that the use of eggshell waste materials in their natural as well as chemically modified forms have provided excellent results for the removal of various classes of dyes [20, 21], oxalic acid [22], phenols [23, 24], pesticides [25], humic acid [26], heavy metals [27, 28] fluorides [29], Phosphorous [30] and PAHs [31]. Most of these applications were tested on batch experiments and focused on synthetic wastewater; Limited work has been reported for the applicability of egghell materials for the treatment of real wastewater or more specifically for the treatment of municipal landfill leachate [32]. Furthermore, little attempts were conducted as well in a form of column experiments $[9,12]$. The motivation of this work is to use calcined eggshell (CES) as a natural adsorbent in a form of continuous flow column experiment to serve as a more cost effective alternative to the current high cost adsorbents used in leachate treatment and thus may open a new vision toward landfill leachate treatment technologies. The overall objective of this study is to assess the potential use of natural eggshell waste material for removal of phenols and PAHs from landfill leachate.

\section{Materials and Methods}

\subsection{Leachate Characterization}

$150 \mathrm{~L}$ of Leachate samples were collected from an active detention pond with a leachate age of less than 5 years at Al-Akaider landfill site located in the Northern part of Jordan. This landfill is an old active site operated since 1981. All samples were collected using plastic containers (20.0 L each), transported directly to the laboratory and stored at $4^{\circ} \mathrm{C}$ before use. All chemical analyses and experimental work for leachate characterization were started within $48 \mathrm{~h}$. Leachate samples were analyzed in triple for selected relevant physico-chemical parameters including $\mathrm{pH}$, electrical conductivity (EC), turbidity, total suspended solids (TSS), particle size distribution (PSD), chemical oxygen demand (COD), biological oxygen demand (BOD), total nitrogen (TN), total phenols, total and specific PAHs.

The $\mathrm{pH}$, EC, Turbidity, TSS, COD, BOD, TN, and total phenols were tested according to the standard method for the examination of water and wastewater [33].The $\mathrm{pH}$ values were measured using 370 JENWAY pH-meters, while the EC measurements have been carried out with 470 JENWAY conductivity meter. The turbidity measurements were conducted using a turbidity meter (Lovibond-PC checkit), while TSS concentration was measured by filtering $1.0 \mathrm{~L}$ of raw leachate through a $0.2 \mu \mathrm{m}$ polycarbonate membrane filter (Osmonics, Inc., CA). PSD was determined using Fritsch Analysette Equipment (analyzer Micro Tec Plus). The COD was tested using closed reflux method (thermo reactor Orion COD125+Titration) and the BOD was tested using 5-day BOD test-Oxitop method. TN was analyzed using Spectroquant NOVA 600. Total phenols were tested using 5550-B (Tannin \& Lignin) while total and specific PAHs were tested according to the standard method for the examination of water and wastewater (SM 6410, 2017) using GC-MS device (Shimadzu-QP2010).

\subsection{Filter Media}

The natural eggshell waste materials (ES) were obtained from local homes and restaurants to serve as filter media. The ES was washed with water to remove impurities, dried for $3 \mathrm{~h}$ at $60^{\circ} \mathrm{C}$, and crushed mechanically in a mixer. The dried eggshell product was calcined (CES) at $750^{\circ} \mathrm{C}$ for $3 \mathrm{~h}$ using muffle furnace (Carbolite, Sheffield-England). GAC, obtained from local market with effective size of $0.71 \mathrm{~mm}$ diameter (Calgon Carbon Corporation, Huntington, WV), was used as the standard filter media to evaluate the adsorptive attributes of CSA. All materials were sieved in a mesh number (40-60) to obtain a grain size diameters ranging from 425-600 $\mu \mathrm{m}$ and stored in a dry box until use. The shape and surface morphology for ES and CES were determined using SEM (FEI QUANTA 600) while mineral composition was determined using X-Ray Fluorescence Analyzer (XRF-FEI QUANTA 600).

\subsection{Jar Test Experiment}

Landfill leachate often contains suspended and colloidal particles with different sizes (0.1-100 $\mu \mathrm{m})$ [1]. Particles are important in the context of fate and transport of contaminants in the environment. Different studies revealed that the organic content of certain colloidal fractions of landfill leachate can sorb significant amounts of hydrophobic organic pollutants (HOPs), causing enhanced movement in subsurface environments and through conventional treat- 
ment processes [34, 35]. So, it has been hypothesized in this research that removing of suspended and colloidal particles from leachate samples by coagulation and flocculation will reduce the concentration of particles and associated organic compounds and consequently will prolong filter running time. The objective of this step was to reduce the TSS concentration in order to allow the next step of the treatment (column experiments) to work effectively without interferences due to suspended particles that might reduce the adsorption performance.

The leachate samples were added first into graduated Imhoff Cone for one hour to allow for any readily settleable solids to settle down by gravity. The supernatant was then taken and treated by coagulation and flocculation using conventional 6 station Jar test apparatus (Stuart-SW6) supplied by 6 beakers (1.0 L each). Alum is used as coagulant material and the optimum dose for TSS removal was predetermined first. $500 \mathrm{~mL}$ of leachate was transferred to each jar-test beaker and then 6 different doses of Alum (0.5-3.0 at 0.5 g/L interval) were added into all beakers. All beakers were subjected to a rapid mixing initially at 120 rpm for $3 \mathrm{~min}$ and slow mixing thereafter at $20 \mathrm{rpm}$ for $30 \mathrm{~min}$. Then the contents of the beakers were allowed to settle by gravity for $1.0 \mathrm{hr}$. The alum dose corresponded to the least turbidity and TSS value was taken as an optimum dose. In this run, the least turbidity and TSS value was observed and measured in beaker No.6 that corresponds to an alum dose of $(3.0 \mathrm{~g} / \mathrm{L})$. Therefore, the experiment was repeated with an alum doses 3.5-6.0 g/L at 0.5 g/L interval. The predetermined optimum dose of alum was then added to all leachate samples and treated in the same manner using Jar test apparatus. The supernatant solution was then withdrawn, collected, and used in the next column experiments. Part of this supernatant solution was filtered through filter paper (Whattmann 40) and tested for the same parameters tested for raw leachate to assess the effect of coagulation on leachate quality. All the experiments and sample analysis were performed in triplicate at room temperature of $25 \pm 1^{\circ} \mathrm{C}$ without $\mathrm{pH}$ adjustment.

\subsection{Column Experiments}

Three Column experiments were conducted in parallel for more than 3 weeks under conditions typical for slow sand filtration (Table S1) using ESC, GAC, and a combination of ESC and GAC at a ratio (3:1) as filter media. The column setup used in this work is presented in Fig. S1 which consists of (a) a solution reservoir containing the leachate pretreated by coagulation-flocculation (b) a peristaltic pump (Cole-Parmer Instrument Co.) (c) a chromatography borosilicate glass column $(\mathrm{d}=2.0 \mathrm{~cm}$ diameter $)$ (Omnifit Supelco, Inc.) packed with the filter media (d) a glass container to collect the effluent liquid. The columns were packed in approximately $2 \mathrm{~mm}$ layers under a head of $5 \mathrm{~mm}$ water. The columns were gently vibrated after each layer was added to redistribute the grains and reduced the porosity. 300 pore volumes (PV) of deionized water were pumped through the column after packing to remove any entrapped air and readily releasable organic colloids. Column porosities determined by the mass of water required for saturation were $0.45,0.48$, and 0.46 for ESC, GAC, and combined ESC-GAC columns respectively. The leachate was delivered to the column with a peristaltic pump using Norprene tubing (Cole-Parmer Instrument Co.) at constant flow rate of $1.25 \mathrm{~mL} / \mathrm{min}$. Column effluent samples were collected daily at fixed time intervals and analyzed for the same parameters tested for raw leachate. The empty bed contact time (EBCT) was 20.0 min which is recommended as a typical design value for GAC contactors (5-30 min) [36]. To prevent the loss of the adsorbent particles, glass wool and wire mesh were placed at the outlet of each column. To ensure that the columns were operating at their design flow rates, the flow rates were checked twice per week.

Based on the experimental data obtained from all column studies, the breakthrough curves were plotted for the normalized concentration $\left(\mathrm{C} / \mathrm{C}_{0}\right)$ with respect to pore volumes (PV). Normalized concentration is dimensionless number corresponds to the effluent concentration $\left(\mathrm{C}_{\mathrm{t}}\right)$ at time $\mathrm{t}$ as a fraction of initial concentration $\left(\mathrm{C}_{0}\right)$. Data from the obtained breakthrough curves were used to estimate the adsorption capacity of the filter media at breakthrough time $\left(q_{b}\right)$ as in Eq. (1).

$$
\mathrm{q}_{\mathrm{b}}(\mathrm{mg} / \mathrm{g})=\frac{\mathrm{M}_{\mathrm{S}}}{\mathrm{M}_{\mathrm{o}}}=\frac{\mathrm{Q} \int_{\mathrm{t}=0}^{\mathrm{t}=\mathrm{tb}}\left(\mathrm{C}_{0}-\mathrm{C}_{\mathrm{t}}\right) \mathrm{dt}}{\mathrm{M}_{0}}
$$

Where $\mathrm{M}_{0}$ is the mass of adsorbent (g), $\mathrm{M}_{\mathrm{S}}$ is the adsorbed mass (mg), and $\mathrm{Q}$ is the flow rate $(\mathrm{L} / \mathrm{min})$. The adsorption capacity at breakthrough time $\left(\mathrm{q}_{\mathrm{b}}\right)$ is estimated when $\mathrm{t}$ is equal to the breakthrough time $\left(\mathrm{t}_{\mathrm{b}}\right)$ which is defined here to be reached when $\mathrm{C}_{\mathrm{t}} / \mathrm{C}_{0}$ satisfy the wastewater discharge limits for studied constituents.

\section{Results and Discussion}

\subsection{Results of ES and ESC Characterization}

SEM and EDS results showing morphological aspects of both ES and ESC materials along with elemental composition are presented in Fig. 1. ES materials have irregular shape with smooth outer surface along with deep and wide cavities containing mainly Ca, C, O and small amount of N, Mg, and P. Detailed focus on eggshell membranes shows the network of interlacing fibers. These cavities and interlacing fibers could provide high specific surface area. A porous, fibril structure, and high surface area of ES was observed by others $[17,18]$ where each ES has been estimated to contain 7,000-17,000 pores. The ESC comprises irregular shape with rough surface and scattered microspores containing mainly $\mathrm{Ca}$ and $\mathrm{O}$ with small amount of $\mathrm{C}$ and $\mathrm{Mg}$. it has been reported that thermal treatment of eggshell at temperature $>700^{\circ} \mathrm{C}$ increases its adsorptive capacity by increasing the surface area. Tsai et al. [19] reported an increase in the surface area of the eggshells from 1.05 to 1.85 $\mathrm{m}^{2} / \mathrm{g}$ and an increase in the particle porosity from 0.018 to 0.051 $\mathrm{g} / \mathrm{cm}$ after calcinations at $1,000^{\circ} \mathrm{C}$.

The obvious reduction in $\mathrm{C}$ content is due to calcinations where $\mathrm{CaCO}_{3}$ has been converted to $\mathrm{CaO}$. This is confirmed by XRF results (embedded as a table in Fig. 1) where $\mathrm{CaCO}_{3}$ is the most abundant component in ES comprising $97 \%$ while $\mathrm{CaO}$ is the predominant one in ESC comprising 93\%. Both ES and ESC contain small amounts 

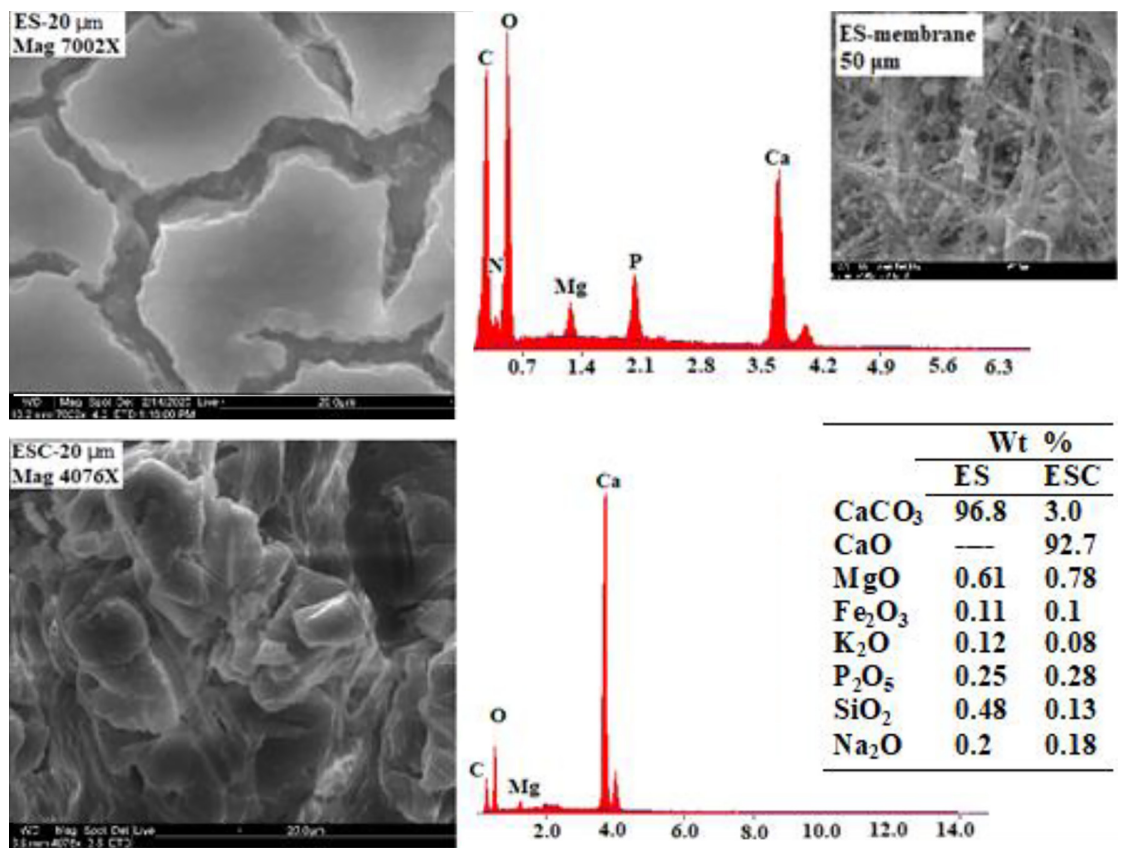

Fig. 1. SEM image and XRF analysis (embedded in the table) of both ES and ESC materials.

of $\mathrm{Fe}_{2} \mathrm{O}_{3}, \mathrm{CuO}, \mathrm{K}_{2} \mathrm{O}, \mathrm{P}_{2} \mathrm{O}_{5}, \mathrm{SiO}_{2}, \mathrm{Al}_{2} \mathrm{O}_{3}, \mathrm{MgO}, \mathrm{Na}_{2} \mathrm{O}$, and $\mathrm{Cl}$ reporting less than $2 \%$ of the total composition.

\subsection{Leachate Characterization}

The properties of raw leachate used in present work are presented in Table1. Generally, the composition of current landfill leachate is of complex nature and characterized by slightly alkaline $\mathrm{pH}$ (6.7), dark colour with high concentrations of biodegradable content as represented by $\mathrm{BOD}_{5}$, and high refractory organic matter as represented by COD. Meanwhile, the presence of high values of BOD and COD in the samples is a clear indication of severe contamination that poses direct threats of groundwater pollution with landfill materials. The relatively high values of EC (Avg $=28,300$ $\mu \mathrm{S} / \mathrm{cm}$ ) indicate the presence of inorganic materials in the samples. The presence of high values of BOD (Avg $=6,530 \mathrm{mg} / \mathrm{L}$ ) and COD (Avg $=38,650 \mathrm{mg} / \mathrm{L})$ indicates high organic strength. BOD/ COD ratio (0.17) suggest that part of the organic material is still biodegradable. Although Biological techniques have been recognized to be very effective for young leachate treatment, the biodegradability ratio commonly decreases as the landfill ages increase and later the biological treatment becomes less effective particularly in presence of persistent and toxic substances that inhibit microbial activities [3-5]. Hence, physicochemical treatment processes become more important.

TN is present at high concentration (Avg $=2,200 \mathrm{mg} / \mathrm{L}$ ) probably due to the deamination of amino acids during the decomposition of organic waste (food, yard, and biosolids) [37]. TSS was detected in all samples at high concentration (Avg $=350 \mathrm{mg} / \mathrm{L}$ ). PSD distinguish 3 groups of particle sizes ranging from $0.3-3.0 \mu \mathrm{m}, 4-20$ $\mu \mathrm{m}$, and 600-1,000 $\mu \mathrm{m}$ (Fig. S2). Density distribution curve shows that about $65 \%$ of the particles are in the size range of $0.3-3.0$ $\mu \mathrm{m}$ whereas $95 \%$ of particles don't exceed $20 \mu \mathrm{m}$.
Phenols were observed in leachate samples at an average concentration of $8.8 \mathrm{mg} / \mathrm{L}$. The PAHs were also detected in all samples at an average total concentration of $7.3 \mathrm{mg} / \mathrm{L}$. Specific PAHs analysis showed the presence of Acenaphthene (ACE), Phenanthrene (PHE), Fluoranthene (FLU), Pyrene (PYR), Benzo (b) fluoranthene (BbF), Benzo (k) fluoranthene (BkF), Benzo (a) pyrene (BaP), Indeno (1,2,3-cd) pyrene (INP), Dibenzo (a,h) anthracene (DBA), and Benzo (g,h,i) perylene (BPY) (Table 1). DBA and PHE were the most abundant PAHs existed in leachate samples comprising $43 \%$ of all PAHs.

\subsection{Jar Test Results}

The effect of alum dose on turbidity and TSS removal is shown in Fig. 2. Removal efficiencies of both turbidity and TSS increased with the increase of alum dose till they reach the highest value (91\% and $82 \%$ for turbidity and TSS, respectively) at a dose of ( $3.5 \mathrm{~g} / \mathrm{L})$ which is assigned here as an optimum dose. At dosage in excess of the optimum value both turbidity and TSS were increased which may be attributed to the restabilization of colloidal particles.

The results obtained from further investigation carried out at this optimum dose $(3.5 \mathrm{~g} / \mathrm{L})$ are presented in Table 1 . The $\mathrm{pH}$ value was decreased slightly from 6.7 to 5.8 after alum addition which may be attributed to the acidic character of $\mathrm{AL}^{+3}$ cation. $\mathrm{COD}, \mathrm{BOD}_{5}$, and $\mathrm{TN}$ were reduced by $32 \%, 30 \%$, and $18 \%$, respectively. It is worth noting that alum addition increased the particle size of suspended material which in turn enhances the settling of suspended matter due to coagulation. PSD of leachate treated by an optimum alum dose shows that most particles $(\approx 98$ $\%$ ) are distributed in the size range 0.3-3.0 $\mu \mathrm{m}$ with only few particles $(\approx 2 \%)$ are in the size range $(200-400 \mu \mathrm{m})$ (Fig. S2). This figure clearly show that all particles that were in raw leachate with size range $(4-20 \mu \mathrm{m})$ are disappeared after coagulation leaving particles 


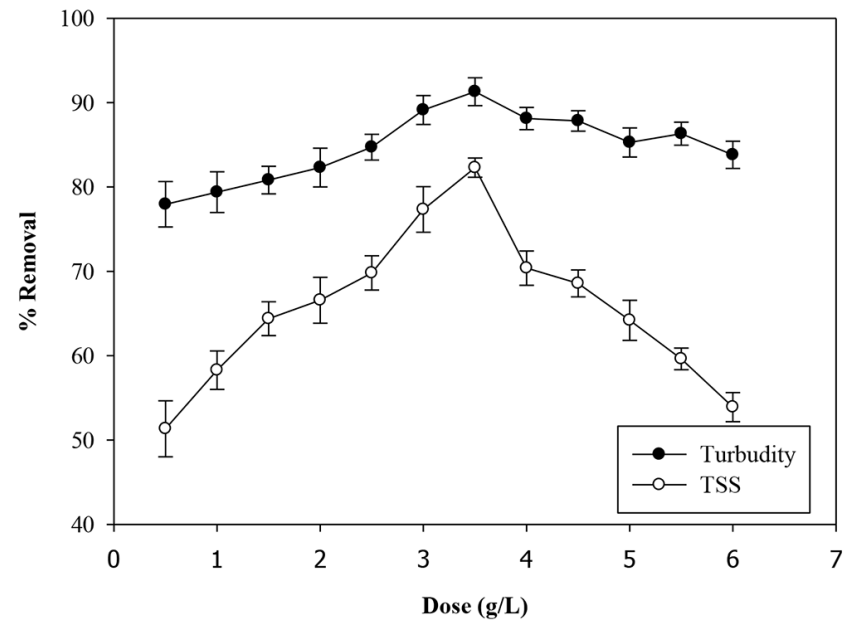

Fig. 2. \% Removal of Turbidity and TSS at different Alum doses. (T $\left.=25^{\circ} \mathrm{C}, \mathrm{pH}=5.8-6.7\right)$

with small sizes $(<3.0 \mu \mathrm{m})$. Consequently, this will affect the removal of some organics that are associated with the suspended solids, so the value of COD was decreased. This pretreatment still produces landfill leachate with high TN concentrations (1800 mg/L). Total phenols were decreased only slightly by $24 \%$ while better reduction was observed for total PAHs (34\%). Some phenolic compounds such as Bisphenols are persistent in nature and frequently found in landfill leachate due to their release from polycarbonate plastics [39]. A study conducted by Aziz et al. [40] on bisphenol removal from landfill leachate revealed a $50 \%$ reduction in Bisphenols at an alum dose of $1.5 \mathrm{~g} / \mathrm{L}$ and $\mathrm{pH}$ of 7.5. PAHs with lower molecular weights (LMW-PAHs) and octanol water partitioning coefficients (Kow) such as ACE and PHE were reduced only slightly by less than $6 \%$ while PAHs with higher molecular weights (HMW-PAHs) and Kow values (INP, DBA, and BPY) were reduced by more than $50 \%$ (Table1). Although, the obtained results are in general trend where more hydrophobic organic compounds have higher affinity to bend to particles, the observed reduction by binding to particles obtained by this work is less than those observed by others [41]. Kalmykova et al. [41] studied the partitioning of PAHs in landfill leachate and found that PAHs are predominantly attached to particles with $43 \%$ for LMW-PAHs and up to $90 \%$ for HMW-PAHs. The lower $\mathrm{PAH}_{\mathrm{s}}$ reduction obtained in this work may be explained by the effect of other pollutants due to complex nature of Alakaider landfill leachate (Table 1).

\subsection{Column Experiment Results}

The flow rates to all columns were held constant $(1.25 \pm 0.02$ $\mathrm{mL} / \mathrm{min}$ ) over the duration of the experiments (3,500 PV). The $\mathrm{pH}$ and EC values of effluent leachate from all columns are presented in Fig. S3. A slight increase in $\mathrm{pH}$ value is observed in the effluent from all columns which may be attributed to the alkaline nature of both activated carbon and ESC materials. Fast reduction in EC was observed in the effluent from all packed media during the first $200 \mathrm{PV}$. Toward the end of the experiment (at 3,500 PV), the EC was reduced by $48 \%, 56 \%$, and $63 \%$ in ESC, ESC-GAC, and GAC columns, respectively.

Table 1. Main Characteristics of Landfill Leachate before and after Coagulation along with \% Reduction [38]

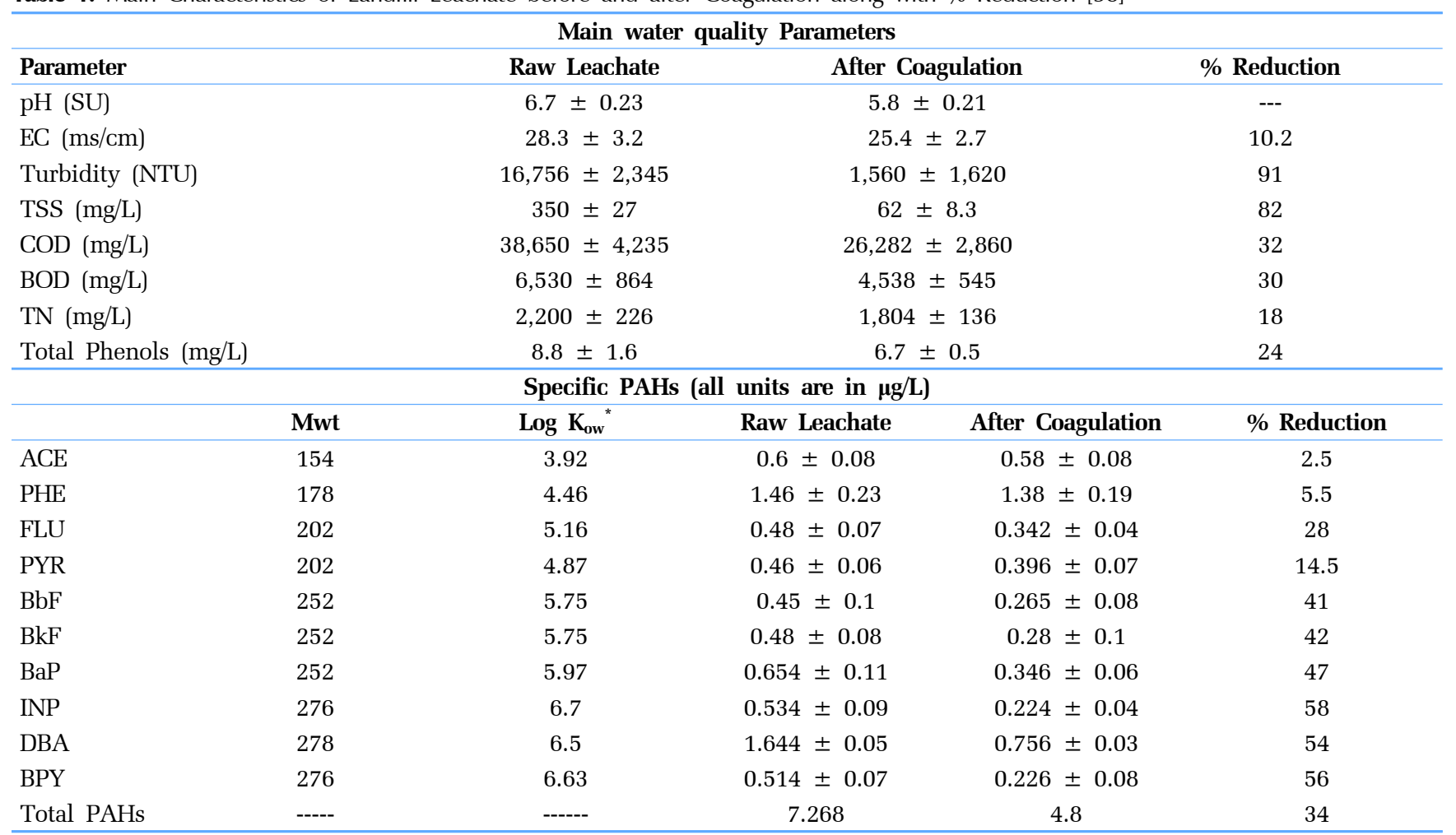


The performance of all fixed bed columns are studied by breakthrough curves, a representation of the loading behavior of the target pollutant onto the adsorbent in a continuous flow column [42]. The breakthrough curves are expressed in this work in terms of the normalized concentration $\left(\mathrm{C} / \mathrm{C}_{\mathrm{in}}\right)$ versus pore volumes (PV). Particles breakthrough curves in all columns are presented in Fig. 3. Based on the effluent TSS analysis, the first evidence of significant breakthrough of particles is observed after 1,200, 1,400, and 1,500 PV in ESC, ESC-GAC, and GAC columns respectively. From these points, effluent TSS concentrations increased continuously in all columns until they reach $60-70 \%$ of the influent concentration at 3,500 PV. At these points, TSS effluent from all columns meets the TSS discharge limit ( $50 \mathrm{mg} / \mathrm{L}$ ) of industrial wastewater.

The breakthrough of organic fraction in all columns outlet presented via COD breakthrough curves is shown in Fig. 4. Fast breakthrough of COD was observed in all columns after 500 PV approaching $<10 \%$ of the initial load at about 1,000 PV (equivalent to $>90 \%$ reduction). However, this removal is insufficient to meet the COD discharge limit $(150 \mathrm{mg} / \mathrm{L})$ of industrial wastewater. After this point, effluent COD concentrations were increased continuously in all columns resulted in reducing the removal efficiencies. For example, at 1,500 PV the COD concentrations were reduced by $70 \%, 80 \%$, and $90 \%$ in ESC, ESC-GAC, and GAC columns, respectively. At the end of the experiments $(3,500$ PV), the COD reduction was $30 \%$ in ESC column and about $40 \%$ in both ESC-GAC and GAC columns. It should be mentioned here that the COD breakthrough, after 1200 PV in ESC column and after 1,500 PV in both ESC-GAC and GAC columns, coincide with TSS breakthrough (Fig. 3). This may be due to binding of some organic substances to particles, a process known in the literature as "colloid-associated contaminant transport" [35, 43, 44]. The relatively low level of COD removal obtained in this work is in agreement with the results obtained by others [45, 46] and may be attributed to the complex nature of Alakaider landfill leachat that resulted in different adsorption affinities. The adsorption sites will be filled first with those constituents of higher adsorption affinity, leaving those with lower adsorption

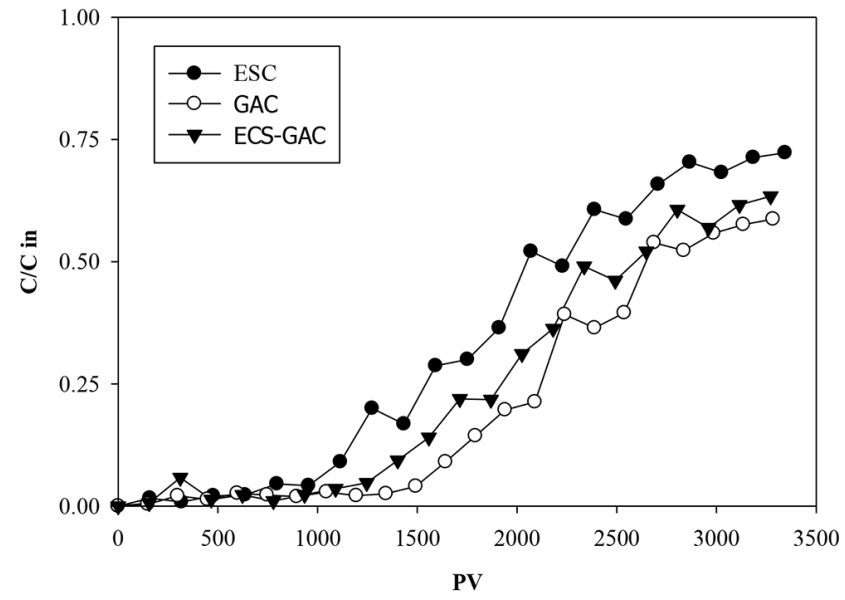

Fig. 3. Breakthrough curves of TSS through filter media. $\left(T=25^{\circ} \mathrm{C}\right.$, $\mathrm{Q}=1.25 \mathrm{~mL} / \mathrm{min}, \mathrm{HLR}=0.4 \mathrm{~cm} / \mathrm{min}, \mathrm{EBCT}=20 \mathrm{~min}$ )

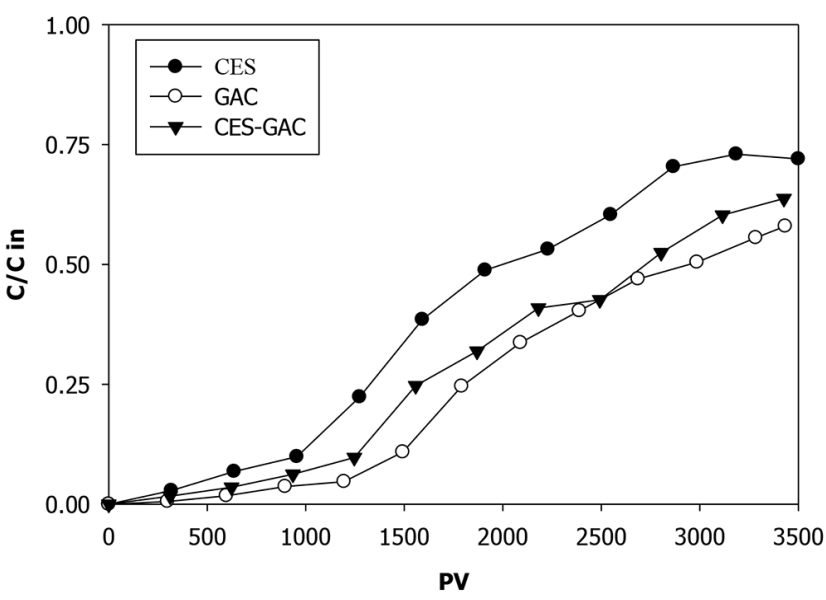

Fig. 4. COD breakthrough curve in all columns. $\left(T=25^{\circ} \mathrm{C}, \mathrm{Q}=1.25\right.$ $\mathrm{mL} / \mathrm{min}, \mathrm{HLR}=0.4 \mathrm{~cm} / \mathrm{min}, \mathrm{EBCT}=20 \mathrm{~min})$

affinity poorly adsorbed [47]. Furthermore, it is well kwon that the adsorption capacity may decrease because of the competition by natural organic matter with different organic contaminants through direct site competition and pore entrance blockage [48].

Breakthrough curves of TN in all columns are presented in Fig. S4. Fast complete breakthrough is attained in all columns after 1,000 PV suggesting negligible efficiency of all media toward TN removal. Only about $10-20 \%$ reductions were obtained after 1,000 $\mathrm{PV}$ and this may be attributed to the increase in $\mathrm{pH}$ value.

The breakthrough curves of phenols through all columns are presented in Fig. 5. The first evidence of considerable phenols breakthrough in all media occur after 1,500 PV. At this point about $95 \%$ of phenols were removed by all media. As time progress breakthrough curves are more dispersed and effluent phenol concentrations increased continuously until the end of the experiment where $70 \%$ of phenols are removed by CES column and $80 \%$ are removed by both GAC and CES-GAC columns. These results indicate that the use of a mixed media (ESC-GAC) had resulted in better performance compared with the use of individual CES media. Although these column experiments were operated under a relatively high loading rate $(1.25 \mathrm{~mL} / \mathrm{min})$, the operating time was insufficient for complete phenols breakthrough at the applied hydrodynamic conditions which suggest that phenols in landfill leachate have a high affinity toward both ESC and GAC materials. This is consistent with the results obtained by others [47-49]. Boukhlifi et al. [48] performed experimental investigations on adsorption of phenol on ES and found ES as a potent, effective adsorbent for phenol molecules in its cavities and pores. Giraldo and Piraján study [49] revealed high sorption capacity of activated carbon obtained from natural eggshell materials reaching up to $192 \mathrm{mg} / \mathrm{g}$. However, under current applied hydrodynamic conditions, complete removal of phenols in all media that satisfy the discharge limit of $0.001 \mathrm{mg} / \mathrm{L}$ was achieved during the first 1,200 PV of column operation. At this point, the adsorption capacities $\left(\mathrm{q}_{\mathrm{b}}\right)$ for CES, CES-GAC, and GAC are 3.26, 3.28, and $3.34 \mathrm{mg} / \mathrm{g}$ respectively suggesting that CES performance is comparable to that of GAC. A comparison of breakthrough adsorption capacity $\left(\mathrm{q}_{\mathrm{b}}\right)$ of CES obtained in this work with those reported by other researchers for various adsorbents are presented in the Table S2. The $q_{b}$ values 


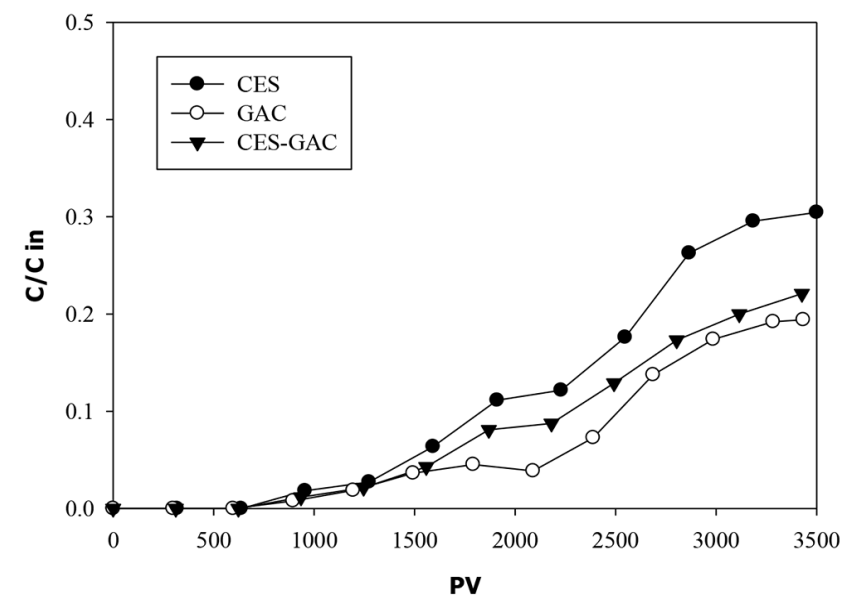

Fig. 5. Breakthrough curves of total phenols in ESC and GAC columns. $\left(\mathrm{T}=25^{\circ} \mathrm{C}, \mathrm{Q}=1.25 \mathrm{~mL} / \mathrm{min}, \mathrm{HLR}=0.4 \mathrm{~cm} / \mathrm{min}, \mathrm{EBCT}=\right.$ $20 \mathrm{~min})$

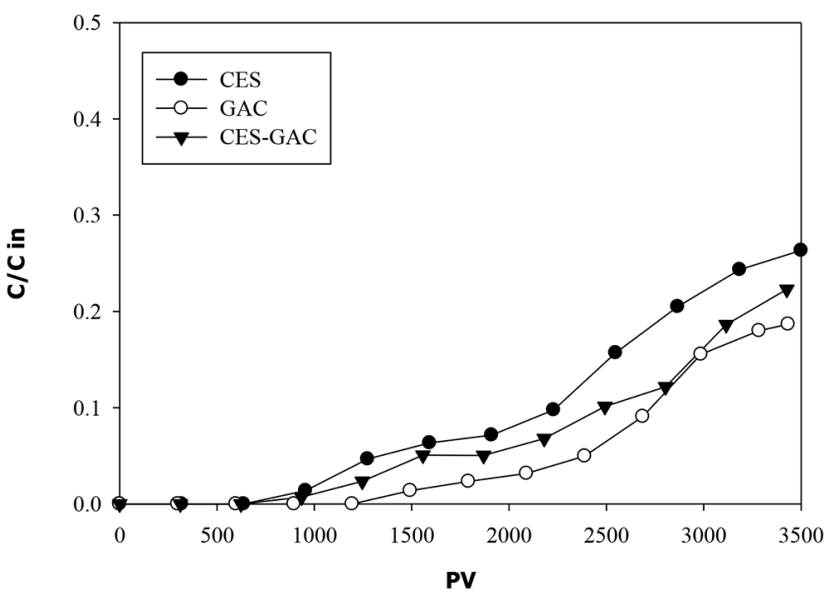

Fig. 6. Breakthrough curves of total PAHs in ESC, ESC-GAC, and GAC columns. $\left(\mathrm{T}=25^{\circ} \mathrm{C}, \mathrm{Q}=1.25 \mathrm{~mL} / \mathrm{min}, \mathrm{HLR}=0.4 \mathrm{~cm} / \mathrm{min}\right.$, $\mathrm{EBCT}=20 \mathrm{~min}$ )

obtained in our work are close to those reported by others but with much longer time to breakthrough which is attributed to the lower HLR and higher EBCT used in our work. At lower HLR one could expect a higher sorption capacity due to longer contact time. At the same time increasing influent concentration was found to have considerable influence on adsorption capacity [50-53]. The influent phenols concentration used in our work $(6.7 \mathrm{mg} / \mathrm{L})$ was much lower than those used by other researchers $(5-100 \mathrm{mg} / \mathrm{L})$ listed in Table S2.

Total PAHs breakthrough curves in all filter media are shown in Fig. 6. The first evidence of PAHs breakthrough occurs after 1,200 PV in both ESC and ESC-GAC columns while it took 1,500 PV to breakthrough in GAC column. These points coincide with TSS breakthrough suggesting that particulate matter may influence the PAHs transport through column media. This finding is in good agreement with those obtained by others [35, 41, 55]. Obvious continuous increase in total PAHs effluent concentrations are observed after 2500 PV until the end of the experiments where $75 \%$ of total
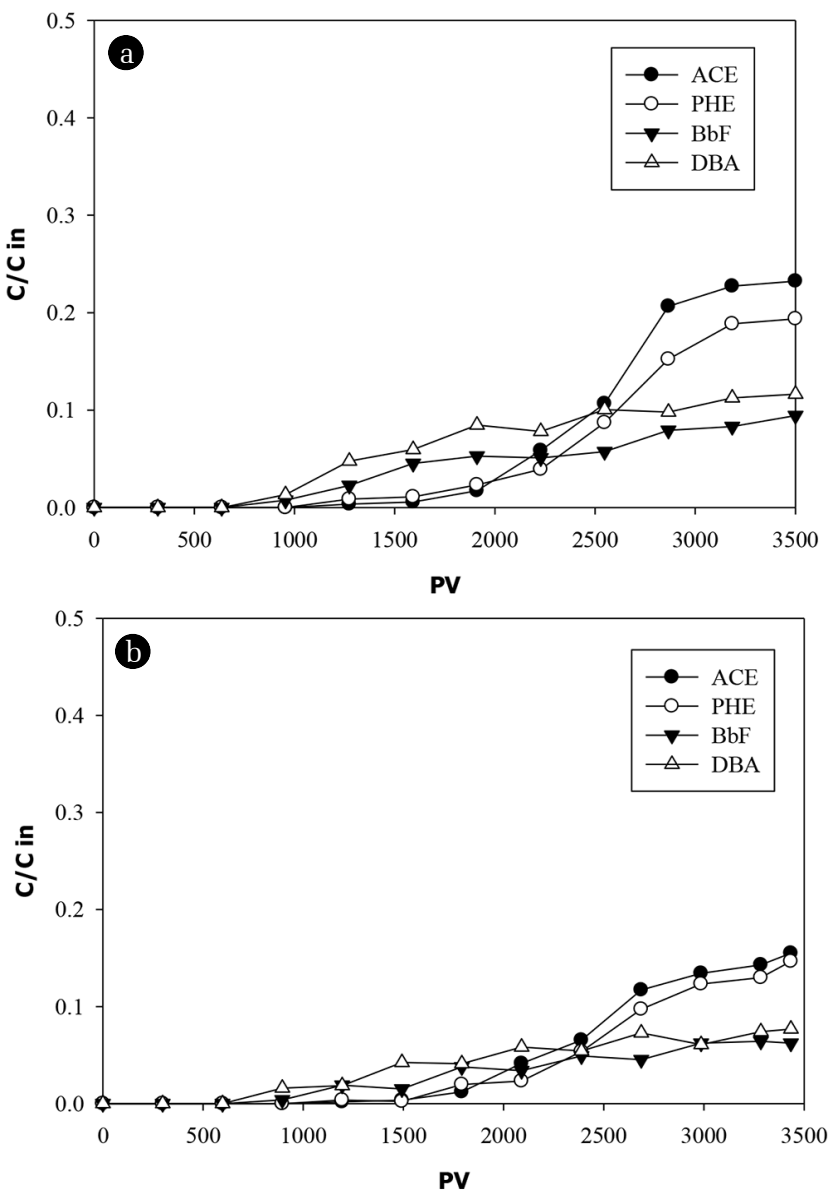

Fig. 7. Breakthrough curves of specific PAHs (ACE, PHE, BbF, DBA) in ESC (a) and GAC (b) columns. $\left(T=25^{\circ} \mathrm{C}, \mathrm{Q}=1.25 \mathrm{~mL} / \mathrm{min}\right.$, $\mathrm{HLR}=0.4 \mathrm{~cm} / \mathrm{min}, \mathrm{EBCT}=20 \mathrm{~min}$ )

PAHs are removed by CES column and $80 \%$ are removed by both GAC and CES-GAC columns suggesting high affinities of PAHs toward both CES and GAC media. Breakthrough curves of 4 specific PAHs (ACE, PHE, BbF, DBA) with different hydrophobicities (Table 1) in ESC and GAC columns are presented in Fig. 7. In ESC column (Fig. 7(a)) fast breakthrough of DBA and BbF (more hydrophobic PAHs) are observed nearly at 1,200 PV which coincide the breakthrough of suspended particles. This may suggest that some molecules of DBA and BbF breakthrough the column at this time due to their association with suspended particles. The results obtained by the jar test showed high binding affinity (> 45\%) of DBA and $\mathrm{BbF}$ toward particles. After this point (1,200 PV) a slight increase in the effluent concentrations is observed reaching only $10 \%$ of the influent concentrations (equivalent to $90 \%$ removal) at 2,500 $\mathrm{PV}$ and being constant thereafter until the end of the experiment $(3,500 \mathrm{PV})$ suggesting high affinity of CES toward DBA and BbF and longer time is still needed to observe the breakthrough of the dissolved part.

Different trends are observed in the breakthrough curves of less hydrophobic PAHs (ACE and PHE). The first evidence of obvious breakthrough of ACE and PHE is observed after 2,200 PV. After 
that point till the end of the experiment, the effluent concentrations were increased rapidly approaching about $20 \%$ of the influent load (corresponds to $80 \%$ reduction). This rapid increase in the effluent concentrations of ACE and PHE after 2,200 PV is properly related to the breakthrough of the dissolved fraction since less hydrophobic compounds usually exhibit less affinity toward particles. This finding is in agreement with the results obtained by others [41, 55] and is confirmed by the results obtained by the jar test where ACE and PHE exhibited weak binding affinity $(<6 \%)$ toward particles compared to that of $\mathrm{BaP}$ and DBA ( $>45 \%$ ) (Table 3). Similar trends are observed for breakthrough of these PAHs in GAC (Fig. 7(b)) and ESC-GAC columns but with a slight better performance where $\approx 95 \%$ and $\approx 85 \%$ removal efficiencies are attained for more hydrophobic PAHs (BaP and DBA) and less hydrophobic PAHs (ACE and PHE), respectively. Although these column experiments were operated under a relatively high loading rate $(1.25 \mathrm{~mL} / \mathrm{min})$, the operating time was insufficient for complete PAHs breakthrough at the applied hydrodynamic conditions which suggest that PAHs in landfill leachate have a high affinity toward both ESC and GAC materials. This is consistent with the results from other studies, which suggested that in cases where affinity of pollutants is very strong, retention factors can be high resulting in longer time to observe the complete breakthrough [56, 57].

It is interesting to mention here that the recommended HLR for onsite wastewater treatment ranges from 30 to $40\left(\mathrm{~L} / \mathrm{m}^{2} \mathrm{~d}\right)$ [58]. In this study, the average HLR equaled $0.4 \mathrm{~cm} / \mathrm{min}$ (equivalent to $5730 \mathrm{~L} / \mathrm{m}^{2}$.d) and it is from 140 to 190 times higher than recommended. If the recommended HLR value was used, it is expected that the sorption obtained from the experiment will increase [50-53] because of longer contact time leading to longer time of contaminant breakthrough.

Overall, the obtained results indicate that ESC particularly when applied as a mixture with GAC can be used as a low cost adsorbent to replace activated carbon in cases where Phenols and PAHs are considered to be the main pollutants. However, for complete treatment of landfill leachate further physical-chemical treatments such as chemical oxidation, reverse osmosis, and or membrane technology are still needed to meet the effluent COD discharge limits. Furthermore, a process as air stripping can be applied as an additional treatment step for $\mathrm{TN}$ removal.

\section{Conclusions}

The composition of Al-Akaider landfill leachate is of complex nature and characterized by dark color with high concentration of COD, phenols, and PAHs indicating a severe potential for groundwater pollution. As an attempt to implement an efficient, cost effective, and environmentally acceptable method for leachate treatment, a sequential treatment consisting of coagulation/flocculation followed by transport column experiment was adopted and used in this work. In column experiments, natural eggshell materials were used as filter media after calcinations at $750^{\circ} \mathrm{C}$ to enhance the microspores and consequently improving its sorption capacity. The results obtained from coagulation/flocculation experiment showed high reduction in turbidity (91\%) and TSS (82\%) when alum is applied at an optimum dose of $3.5 \mathrm{~g} / \mathrm{L}$. At this dose, concentrations of COD, Phenols, and PAHs were affected by particles removal and reduced by $32 \%, 24 \%$ and $34 \%$, respectively. The results obtained from column experiments revealed that, under current applied hydrodynamic conditions, complete removal of phenols in all media that satisfy the wastewater discharge limit is achieved during the first 1,200 PV of column operation, while $70-80 \%$ removal is attained at the end of the experiment (3,500 PV). Furthermore, the obtained results showed high affinity of CES toward PAHs with removal efficiencies ranging from $80 \%$ for ACE and PHE (less hydrophobic) to $90 \%$ for DBA and BbF (more hydrophobic).

The results obtained from the transport column experiments indicate that ESC particularly when applied as a mixture with GAC can be used as an efficient and cost effective adsorbent for landfill leachate treatment in cases where phenols and PAHs are considered to be the main pollutants. However, further treatment step is still needed for COD removal in order to meet the effluent discharge limits. Furthermore, a process as air stripping can be applied as an additional treatment step for TN removal.

\section{Acknowledgment}

The authors acknowledge the Scientific Research Support Fund at Yarmouk University for their financial support, the crew at civil engineering department for their kind cooperation, and the laboratory crew at the Department of Archaeology for their cooperation in analytical work. Special thanks as well to the laboratory crew at Royal scientific Society of Jordan for their cooperation in analytical work.

\section{Authors Contributions}

J.A.Q. (Associate Professor) designed the experimental work and wrote the manuscript. J.A.Q. (Associate Professor) and S.A.R. (Master Student) conducted all experimental work. S.O.(Associate Professor) revised the manuscript and conducted PSD test.

\section{References}

1. Kamble BS, Saxena PR. Environmental impact of municipal dumpsite leachate on ground-water quality in Jawaharnagar, Rangareddy, Telangana, India. Appl. Water Sci. 2017;7:33333343.

2. Marttinen SK, Kettunen RH, Sormunen KM, Soimasuo RM, Rintala JA. Screening of phycial-chemical methods for removal of organic material, nitrogen and toxicity from low strength landfill leachates. Chemosphere 2002;46:851-858.

3. Pokhrel D, Viraraghavan T. Leachate generation and treatment-A review. Fresenius Environ. Bull. 2004;13:223-232.

4. Melike YK, Kadir K,Taner Y. Landfill leachate treatment by the combination of physicochemical methods with adsorption process. J. Biol. Environ. 2007;1:37-43.

5. Ozturk I, Altinbas M, Koyuncu I, Arikan O, Gomec YC. Advanced physico chemical treatment experiences on young municipal landfill leachates. Waste Manage. 2003;23:441-446. 
6. Assou M, Madenzi A, Anouzla A, Aboulhassan MA, Souabi S, Hafidi M. Reducing pollution of stabilized landfill leachate by mixing of coagulants and flocculants: A comparative study. Int. J. Eng. Innov. Technol. 2014;4:20-25.

7. Kargi F, Pamukoglu MY. Powdered activated carbon added biological treatment of pre-treated landfill leachate in a fed-batch reactor. Biotechnol. Lett. 2003;25:695-699.

8. Bashir MJ, Xian TM, Shehzad A, Sethupahi S, Aun NC, Amr SA. Sequential treatment for landfill leachate by applying coagulation-adsorption process. Geosystem Eng. 2017;20:9-2

9. El-mouhri G, Merzouki M, Kachkoul R, et al. Fixed-bed adsorption of tannery wastewater pollutants using bottom ash: An optimized process. Surf. Interfaces. 2021;22:100868.

10. Isa MH, Lee SL, Asaari FA, Aziz HA, Ramli NA, Dhas JP. Low cost removal of disperse dyes from aqueous solution using palm ash. Dyes Pigm. 2007;74:446-453.

11. Wen J, Dong H, Zeng G. Application of zeolite in removing salinity/sodicity from wastewater: A review of mechanisms, challenges and opportunities. J. Clean. Prod. 2018;197:1435-1446.

12. El-mouhri G, Merzouki M, Miyah Y, et al. Valorization of two biological materials in the treatment of tannery effluents by filtration Treatment of tannery effluents by filtration. Mor. J. Chem. 2019;7:183-193.

13. Elmountassir R, Bennani B, Miyah Y, et al. Microbiological and Physicochemical Characterization of Hospital Effluents before and after Treatment with Two Types of Sawdust. Hindawi J. Chem. 2019;3275101:1-10.

14. Hussain S, Aziz HA, Isa $\mathrm{MH}$, Adlan MN, Asaari FA. Physico-chemical method for ammonia removal from synthetic wastewater using limestone and GAC in batch and column studies. Bioresour. Technol. 2007;98:874-880.

15. Miyah Y, Lahrichi A, Kachkoul R, et al. Multi-parametric filtration effect of the dyes mixture removal with the low cost materials. Arab. J. Basic Appl. Sci. 2020;27:248-258.

16. Zhang X, Zhou J, Yang D, Chen S, Huang J, Li Z. $\mathrm{Cu}_{2}-\mathrm{xS}$ loaded diatom nanocomposites as novel photocatalysts for efficient photocatalytic degradation of organic pollutants. Catal. Today. 2019;335:228-235

17. William JS, Owen JC. Egg Science and Technology, 4th edition, CRC Press, Boca Raton, Florida; 1995.

18. Torres FG, Troncoso OP, Piaggio F, Hijar A. Structure-property relationships of a biopolymer network: The eggshell membrane. Acta Biomater. 2010;6:3687-3693.

19. Tsai WT, Yang JM, Lai CW, Cheng YH, Lin CC, Yeh CW. Characterization and adsorption properties of eggshells and eggshell membrane. Bioresour. Technol. 2006;97:488-493.

20. Elkady MF, Ibrahim AM, El-Latif MM. Assessment of the adsorption kinetics, equilibrium and thermodynamic for the potential removal of reactive red dye using eggshell biocomposite beads. Desalination 2011;278:412-423.

21. Hasan R, Ahliyasah NA, Chong CC, Jusoh R, Setiabudi HD. Egg-shell Treated Oil Palm Fronds (EG-OPF) as Low-Cost Adsorbent for Methylene Blue Removal. Bull. Chem. React. Eng. Catal. 2019;14:158-164.

22. Ikram M, Rehman AU, Ali S, Ali S, Bakhtiar SU, Alam S. The adsorptive potential of chicken egg shells for the removal of oxalic acid from wastewater. J. Biomed. Eng. Inform.
2016;2:118-131.

23. Boukhlifi F, Chraibi S, Alami M. Evaluation of adsorption kinetics and equilibrium for the potential removal of phenol using a new biosorbent. J. Environ. Earth Sci. 2013;3:181-191.

24. Chraibi S, Moussout H, Boukhlifi F, Ahlafi H, Alami M. Utilization of Calcined Eggshell Waste as an Adsorbent for the Removal of Phenol from Aqueous Solution. J. Encapsulation Adsorp. Sci. 2016;6:132-146

25. Elwakeel KZ, Yousif AM. Adsorption of malathion on thermally treated egg shell material. Water Sci. Technol. 2010;61:10351041.

26. Zulfikar MA, Novita E, Hertadi R, Djajanti SD. Removal of humic acid from peat water using untreated powdered eggshell as a low cost adsorbent. Int. J. Environ. Sci. Technol. 2013;10: 1357-1366.

27. Daraei H, Mittal A, Mittal J, Kamali H. Optimization of Cr(VI) removal onto biosorbent eggshell membrane: experimental and theoretical approaches. Desalin. Water Treat. 2014;52:13071315.

28. Ravi T, Sundararaman S. Synthesis and characterization of chicken eggshell powder coated magnetic nano adsorbent by an ultrasonic bath assisted co-precipitation for $\mathrm{Cr}(\mathrm{VI})$ removal from its aqueous mixture. J. Environ. Chem. Eng. 2020;8:103877

29. Bhaumik R, Mondal NK, Das B, et al. Eggshell Powder as an Adsorbent for Removal of Fluoride from Aqueous Solution: Equilibrium, Kinetic and Thermodynamic Studies. E-J. Chem. 2012;9:1457-1480

30. Kim D, Kim Y, Choi J, Ryoo KS. Evaluation of Natural and Calcined Eggshell as Adsorbent for Phosphorous Removal from Water. Bull. Korean Chem. Soc. 2020;41:650-656

31. Wang W, Chen B, Huang Y. Eggshell membrane-based biotemplating of mixed hemimicelle/admicelle as a solid-phase extraction adsorbent for carcinogenic polycyclic aromatic hydrocarbons. J. Agric. Food Chem. 2014;62:8051-8059.

32. Erika Z, Icela DB, Sergio G, Manuel B, Hugo E, Jesús MS. Adsorption kinetics of matter contained in a leachate using eggshell and activated carbon. J. Environ. Prot. 2014;5:608-619.

33. APHA. Standard Methods for examination of water and wastewater. 22nd ed. American Public Health Association (APHA), American water works Association (AWWA) and Water Environment Federation (WEF), Washington, D.C, USA, 2012.

34. Grolimund D, Borkovec M, Barmettler K, Sticher H. Colloid-facilitated transport of strongly sorbing contaminants in natural porous media: A laboratory column study. Environ. Sci. Technol. 1996;30:3118-3123.

35. Jaradat AQ, Fowler K, Grimberg SJ, Holsen TM. Transport of colloids and associated hydrophobic organic chemicals through a natural media filter. J. Environ. Engrg. 2009;135:36-45.

36. Tchobanoglous G, Burton F, Stense H. Wastewater engineering: treatment and reuse. 4th Ed.Metcalf and Eddy Inc; McGraw-Hill, New York; 2003.

37. Tatsi AA, Zouboulis AI. A field investigation of the quantity and quality of leachate from a municipal solid waste landfill in a Mediterranean climate (Thessaloniki, Greece). Adv. Environ. Res. 2002;6:207-219.

38. Mackay D, Callcott D. Partitioning and physical chemical properties of PAHs. In Neilson, A., ed. PAHs and Related Compounds. 
The Handbook of Environmental Chemistry. Springer Berlin Heidelberg. 1998. p. 325-345.

39. Björnsdotter MK, Boer DJ, Gómez AB. Bisphenol A and replacements in thermal paper: A review. Chemosphere 2017;182:691706.

40. Aziz A, Agamuthu P, Fauziah SH. Removal of bisphenol A and 2,4-Di-tert-butylphenol from landfill leachate using plantbased coagulant. Waste Manag. Res. 2018;36:975-984.

41. KalmykovaY, BjorklundK, Stromvall AM, Blom L. Partitioning of polycyclic aromatic hydrocarbons, alkylphenols, bisphenol A and phthalates in landfill leachates and stormwater. Water Res. 2013;47:1317-1328.

42. Patel H. Fixed-bed column adsorption study: a comprehensive review. Appl. Water Sci. 2019;9:45.

43. Bekhit HM, Hassan AE. Two-dimensional modeling of contaminant transport in porous media in the presence of colloids. Adv. Water Resour. 2005;28:1320-1335.

44. Jaradat AQ, Grimberg SJ, Holsen TM. Colloidal transport through natural filter media. J. Environ. Eng. 2009;135:544-550

45. Adinata D, Wan Daud WM, Aroua MK. Preparation and characterization of activated carbon from palm shell by chemical activation with K2CO3. Bioresour. Technol. 2007;98:145-149.

46. Apul OG, Wang Q, Zhou Y, Karanfil T. Adsorption of aromatic organic contaminants by graphene nanosheets: Comparison with carbon nanotubes and activated carbon. Water Res. 2013;47:1648-1654.

47. Daraei H, Mittal A, Noorisepehr M, Daraei F. Kinetic and equilibrium studies of adsorptive removal of phenol onto eggshell waste. Environ. Sci. Pollut. Res. 2013;20:4603-4611.

48. Boukhlifi F, Chraibi S, Alami M. Evaluation of adsorption kinetics and equilibrium for the potential removal of phenol using a new biosorbent. J. Environ. Earth Sci. 2013;3:181-191.

49. Giraldo L, Piraján JC. Study of adsorption of phenol on activated carbons obtained from eggshells. J. Anal. Appl. Pyrolysis 2014; 106:41-47.

50. Iheanacho CO, Nwabanne JT, Obi CC, Onu CE. Packed bed column adsorption of phenol onto corn cob activated carbon: linear and nonlinear kinetics modeling. S. Afr. J. Chem. Eng. 2021;36:80-93

51. Vazquez G, Alonso R, Freire S, Gonzalezalvarez J, Antorrena G. Uptake of phenol from aqueous solutions by adsorption in a Pinus pinaster bark packed bed. J. Hazard. Mater. 2006;133: 61-67.

52. Karunarathne H, Amarasinghe B. Fixed bed adsorption column studies for the removal of aqueous phenol from activated carbon prepared from sugarcane bagasse. Energy Procedia. 2013;34: 83-90.

53. Muthamilselvi P, Karthikeyan R, Kapoor A, Prabhakar S. Continuous fixed-bed studies for adsorptive remediation of phenol by garlic peel powder. Int. J. Ind. Chem. 2018;9:379-390.

54. Talib MI, Chauhan YP, Parate VR. Packed Bed Adsorption study on phenol removal and its modeling. In: Advance Materials, Textiles and processes(ICAMTP-2017); 14-15 October 2017; Kanpur, India.

55. Chávez RP, Pizarro EC, Galiano YL. Landfill leachate treatment using activated carbon obtained from coffee waste. Eng. Sanit. Ambient 2019;24:833-842.

56. Brownawell BJ, Hua C, Collier JM, Westall JC. Adsorption of organic cations to natural materials. Environ. Sci. Technol. 1990;24:1234-1241

57. Copenhaver SA, Krishnaswami S, Turekian KK, Epler N, Cochran JK. Retardation of 238U and 232Th decay chain radionuclides in Long Island and Connecticut aquifers. Geochim. Cosmochim. Acta. 1993;57:597-603.

58. USEPA. Onsite wastewater treatment systems manual. EPA/ 625/R-00/008; 2002. 